Journal of Engineering and Applied Sciences 15 (1): 114-127, 2020

ISSN: 1816-949X

(C) Medwell Journals, 2020

\title{
Production of Ceiling Tile with High Density Polyethylene (HDPE) and Polyethylene Terephthalate (PET) Plastic Wastes as Main Ingredients
}

\author{
${ }^{1}$ Koleoso Akinpelu Olujide, ${ }^{2}$ Edmond O. Anaele, ${ }^{2}$ Godwin Keres Okereke and ${ }^{2}$ Hyginus Osita Omeje \\ ${ }^{1}$ Department of Technical Education, Tai Solarin College of Education, \\ Omu Ijebu, Ogun State, Nigeria \\ ${ }^{2}$ Department of Industrial Technical Education, Faculty of Vocational and Technical Education, \\ University of Nigeria, Nsukka, Nigeria
}

\begin{abstract}
This study focused on the production of ceiling tile with High Density Polyethylene (HDPE) and Polyethylene Terephthalate (PET) plastic wastes as main ingredients. The study was conducted in Ogun State of Nigeria. Six research questions guided the study. The study adopted Research and Development (R and D) design. A Discarded Polyethylene Terephthalate (PET) and High-Density Polyethylene (HDPE) plastic s was used. Four trail productions with 1.5, 2.0,3.0 and $2.5 \mathrm{~kg}$ quantity of material was used to determine the exact quantity of PET and HDPE materials needed. This gave $2.5 \mathrm{~kg}$ as the exact production material quantity needed for the study. Also, the mixing proportion ratio of 1:4 of HDPE and PET plastic waste was determined for stable product. The test result on recycled revealed that HDPE and PET ceiling tile have $0.7 \%$ water absorption rate, impervious water permeability, flexural test of $1.31 \mathrm{MPa}$, a density of $1.3 \mathrm{mg} \mathrm{cm}^{-3}$, slightly smooth texture and it can be painted, sawn and sandpapered. The findings showed that the choice of HDPE and PET plastic wastes as materials contributed in producing a ceiling tile type for building construction. In addition, it was also revealed that casting method of producing plastic was used to produce recycled HDPE and PET plastic ceiling tiles. Based on these findings, the following recommendations were made: production of recycled HDPE and PET ceiling tile to serve as means of internal generation of revenue for the TVET based institutions, Ogun State Ministry of Education to integrate the production of recycled High-Density Polyethylene (HDPE) and Polyethylene Terephthalate (PET) plastic ceiling tile, in vocational training centres of the state among others.
\end{abstract}

Key words: Ceiling tile, High Density Polyethylene (HDPE), Polyethylene Terephthalate (PET), plastic wastes, recycling, building construction

\section{INTRODUCTION}

Building is one of the products of technology and an essential need of every member of a society. Relatively, building should not be costly to procure and should provide necessary comfort for the users. As stated in the document of the Federal Emergency Management Agency (FEMA) (2015), a building can be defined as an enclosed structure intended for human occupancy. A building is made up of the structure itself and non-structural components like cladding, interior walls and ceilings. According to Bachman and Dowty (2008) many structural components assembled on site to make up building include ceiling tiles, partition walls and exterior curtain walls. Thus, a building is composed of various components including ceiling tiles that serve different purposes for the building users.

Ceiling is an essential part of a building. Seeley (2010) presented a type of ceiling as that composed of reinforced concrete or precast concrete slabs and beams above floor level. Thus, ceiling is not a structural element but a finished surface concealing the underside of suspended floor or roof. Chuldley and Greeno (2014) also stated that, ceiling is one of the secondary elements (non-structural components) in a building which is attached to the underside of suspended floor or roof above. Hence, ceiling has its own functions in buildings. On the one hand, CGC (2010) reveals some functions of ceiling that include aesthetics, acoustic control, durability, fire-resistance, thermal insulation and accessibility to the plenum in the case of drop ceilings. However, to achieve some of the functional needs of a ceiling tile, the ceiling tiles must possess good work ability property. This is because a ceiling tile may need to be sawn, sandpapered and painted. However, sandpapering or painting is not applicable on some ceiling tiles as they were factory treated with necessary features for good outlook. The work ability property enables further manipulation of ceiling tiles to attain desired good outlook and easy fixing during construction. To achieve effective performance of ceiling tiles, effective material with suitable properties is needed. The materials used for the building components determine the comfort in a

Corresponding Author: Hyginus Osita Omeje, Department of Industrial Technical Education, 
building. It is also stated that, effective performance of a ceiling in buildings depends on the material used. The type of material used therefore is a determinant of behaviour and performance of a component for which it is used. Material is generally believed to be anything used to make something. It could be raw (natural) or processed types. Bergman and Bourell (2013) stated that, material is generally accepted to be anything which is a finished product on its own or an unprocessed raw material, it becomes processed material when manipulated. This implies that, materials are of two categories: Fundamental or raw and processed material. Seeley (2010) stated that, the common materials used for ceiling tiles/boards are asbestos, wood (solid or manufactured), Polyvinyl Chloride (PVC) and Plaster of Paris (POP). SABISA (2013) outlined standard materials for use in ceiling construction as plasterboard, plasterboard cove cornice, softwood rendering and batten, fibre-cement board and softwood studs for timber frame in buildings. These outlined materials possess different properties that include absorption of moisture and swelling, brittleness, fibrous and high cost. Such characteristics pose problems of maintenance/procurement and health to the building owners and users.

Materials used in construction of a building are not expected to endanger human health in any form, both during construction and while dwelling in the building. In the cause of abrading or sawing of materials, particles in form of dust are released and moved about by the air which can be inhaled by human beings. OSHA (2002) stated that asbestos particles enter human body through inhalation which can course disabling or fatal diseases such as asbestosis, an emphysema-like condition, lung cancer, mesothelioma, a cancerous tumor that spreads rapidly in the cells of membranes covering the lungs and body organs and gastrointestinal cancer. OSHA (2002) concluded that, the symptoms of these diseases generally do not appear until twenty five or more years, after the initial exposure. Asbestos is among the commonly used materials for ceiling board in Ogun State, it also possesses moisture absorbent property. As a result asbestos is not a very good material for the production of ceiling board.

The characteristics of climatic condition include the movement of moisture during wet seasoning. Any absorbent material used in a building can absorb moisture during wet season and releases the moisture by evaporation into the rooms. WSDH (2011) does not support the use of absorbent materials for ceiling board in a dwelling place. Asbestos, Plaster of Paris (POP) and wood which include the common materials in use for ceiling board are absorbent materials. The retained water in these materials dries by evaporation that, releases contaminated moisturized gas into the room and which is dangerous to human health (OSHA, 2002). Major among the poor characteristics of Polyvinyl Chloride (PVC) ceiling tiles is low heat resistance, this property makes PVC ceiling tile unsuitable for Ogun State of Nigeria, with occasional hot weather (dry season period) condition. Newman et al. (2009) made it known that Africa is the most tropical (hot) of the world continents. Since Ogun State is found in Nigeria which is in Africa, therefore, it is necessary to look for means of reducing negative effect of heat, in residential buildings in Ogun State. In addition, PVC ceiling tile is relatively expensive because its production is still under the control of Foreign companies.

Researcher's visitations to some plastic industries that include Alkem Nigeria limited, Geepee and Veepee plastic industries and golden silk industry (producer of PVC ceiling tiles), revealed that the companie's main aspect of production is under the control of Foreign experts. It was established at Veepee plastic industry that, there is Foreign and Nigerian production manager. Foreign production manager performs sensitive production aspect that is unknown to Nigerian production manager. Record of GS (2011) revealed that the production of Polyvinyl Chloride (PVC) plastic ceiling tiles in Nigeria started in 2006, when Golden Silk Nigeria limited concluded the registration agreement on the production of the commodity under the license of the Chinese based company. Thus, PVC ceiling tiles originated from a Foreign country and its production is mainly under the control of the parent company. Plasopan (2004) stated that Polyvinyl Chloride (PVC) ceiling tile has various advantages over other materials, these include waterproof, termite proof and maintenance free, being non-porous and non-absorbent, it can incorporate flush and fitting light-points. Revelation through Plasopan includes the advantages that can be derived from the use of plastic for ceiling tile.

The common available types of plastics include Polyvinyl Chloride (PVC), High Density Polyethylene (HDPE) and Polyethylene Terephthalate (PET or PETE) with different properties. Berins (1991) stated that, Polyethylene Terephthalate (PET) possesses higher heat resistance property than Polyvinyl Chloride (PVC) while High Density Polyethylene (HDPE) possesses heat resistance lesser than PET and higher than PVC. Rutland (2015) stated that PET plastic combines excellent mechanical, electrical and thermal properties with very good chemical resistance and dimensional stability. On the other hand, Rutland (2015) stated that PVC is not reliably load bearing above $60^{\circ} \mathrm{C}$ and requires the addition of some other types of plastics to improve its heat resistance property. Thus, PET and HDPE plastics possess more heat resistance advantage than PVC plastic as material for ceiling tile in tropical areas which includes Ogun State in Nigeria. Manipulation of material during 
production also matters as there are different ways by which materials can be worked on to suit a purpose. Generally, plastics are produced through melting and moulding processes. While thermosetting plastic cannot be re-melted after the initial production, thermoplastic plastics can be re-melted and re-moulded. Klein (2011)stated that unlike thermosetting plastic, thermoplastics can be reversibly melted by heating and re-solidified by cooling without significant changing of mechanical and optical properties. Klein (2011) stated further that thermosetting plastics can be ground and mixed with mouldable material in recycling as additive. Additive is a material used in addition to the main production material to improve the quality of the product. It is mainly to control the properties, enhance aesthetic or reduce the cost of production. Bart (2005) stated that, additive is a substance which is incorporated into plastic to achieve a technical effect in the finished product and it is intended to be an essential part of the finished article. Thus, additive includes other types of plastic or non-plastic materials, with a property that can be used to control the properties of the main production material, used for a product. Fox (2008) outlined different types of additives that include stabilizers, processing aids, plasticizers, antistatic agents, blow agents, fillers and coupling agents. Addition of additive (s) to a plastic material during production enables dynamic suitability of plastic for different purposes. However, the availability of materials for the ceiling tile production maters, for the purpose of consistency of the production.

Polyethylene Terephthalate (PET) and High Density Polyethylene (HDPE) include the most common disposed waste plastic bottles and containers found around in Ogun State. Aderogba (2014) also stated that, common among the wastes that litter every city and town recently in Nigeria are polymers of various types. These are different PET plastic bottles of soft drinks that include that of coca-cola, pepsi-cola, shewepps and table water plastic bottles. Other sets of plastic waste products made of HDPE plastic found around include that of used crank oil kegs, cosmetic containers of various types and milk jugs. The sign that shows the type of plastic used for a purpose appears at the base of plastic products for identification reason. There are established waste plastics processing centers in Ogun State. These include Onihale plastic wastes processing centre in Ifo local government area, Ogun State. Waste plastic products of different kinds are crushed into chips at these centres and sold to those who may want to recycle them. This shows that Ogun State is blessed with abundance of waste plastic products. Hence, there is need for purposeful production of ceiling tile with PET and HDPE plastic wastes to turn these wastes to wealth in Ogun State. Production equipment refers to the necessary items that include tools/machines and other items needed for a particular production purpose. It is the method of production that determines the production equipment. Different types of equipment are in use for production of the available ceiling boards. Each type of equipment was determined by the method/treatment used to manipulate the production material to assume the desired product. The equipment and method used in wooden ceiling board, is the usual woodworking method and the tools. This includes method of sawing and shaping wood to the sizes and shapes desired for a ceiling board. Plaster of Paris (POP) comes in powdery form that requires mixture with water, to form paste that is put in a mould of required shape, till it hardens up. Asante-Kyei (2012) stated that, the use of POP for ceiling board requires the equipment for mixing POP powder to form paste and the mould that enables the paste to form the desired shape and size needed as a ceiling board. Thus, the equipment used in the method of obtaining ceiling board through POP are mixing apparatus and mould designed to desired size and shape of a ceiling tile. Production equipment also includes the machines/tools used for testing the product for quality control and standardization. Locally designed and fabricated equipment was considered for the production of HDPE and PET ceiling tile.

It was against this background that it became necessary to embark on a research towards production of a ceiling tile, with High Density Polyethylene (HDPE) and Polyethylene Terephthalate (PET) plastic s wastes as ingredients. This was to make the production of ceiling tile with HDPE and PET plastics wastes common and locally possible. It was also to look for possible means of reducing the cost of building procurement and production of health and environment friendly building material.

Purpose of the study: The major purpose of this study was to produce ceiling tiles, with the use of HDPE and PET plastic wastes as major ingredients. Based on the purpose of this study, the following specific research questions were answered for the study:

- What are the standard properties of ceiling tile in the High Density Polyethylene (HDPE) and Polyethylene Terephthalate (PET) plastics production materials, for a ceiling tile?

- What exact quantity of HDPE and PET plastic production materials is adequate for the production of ceiling tile, for the purpose of cost effectiveness?

- What mixing proportion of HDPE and PET plastics production materials would meet the adhesive and flexural property of a ceiling tile?

- What production method is most appropriate for the production of recycled HDPE and PET plastic ceiling tile?

- What are the properties of the produced recycled HDPE and PET plastics ceiling tile? 
- What are the differences in the qualities of recycled HDPE and PET plastic ceiling tile and the common available ceiling tiles which are asbestos, Plaster of Paris (POP) and Polyvinyl Chloride (PVC)?

\section{MATERIALS AND METHODS}

Design of the study: The Research and Development (R and $\mathrm{D}$ ) design was adopted for the study. According to Nworgu (2006), R and D is a process through which books, equipment or curricula are developed and trial-tested in the fields to ensure their effectiveness. The $\mathrm{R}$ and $\mathrm{D}$ is a research method that brings about new-improved products and better method of production. $\mathrm{R}$ and $\mathrm{D}$ is usually an industrial means of progressing and developing products for better service to the society. Research and development was chosen as appropriate for this study because the focus was to produce a new brand of ceiling board using High Density Polyethylene (HDPE) and Polyethylene Terephthalate (PET) plastic wastes as major components.

Design procedure: The identified procedural steps adapted in the design of this study were the steps adapted by Afuwape (2013). This is because the nature of phenomenon under investigation with $\mathrm{R}$ and $\mathrm{D}$ determines the approach and the steps to follow. The adapted steps are as follows: methods in use, method used in the study, the production process, identification of details of design, task involved, description and development of the recycled HDPE and PET ceiling board prototype, tests techniques, decisions on the study tests.

Area of the study: The study was carried out in Ogun State of Nigeria. Ogun State shares boundary with Lagos State in the South, Republic of Benin in the West, Ondo State in the East and Oyo State in the North. The State is an industrial area with Abeokuta as the capital. There are different buildings under construction in different locations in Ogun State. Majority of these new buildings are already occupied without ceiling. The reason given by the occupants of these buildings is the high cost of ceiling tile/board which is beyond the reach of the affected citizens of Ogun State. In addition High Density Polyethylene (HDPE) and Polyethylene Terephthalate (PET) plastics wastes are found in abundance in Ogun State, occupying water ways, streets and road sides. This made the researcher undertook this study in Ogun State, in order to access the discarded HDPE and PET plastic for the production of ceiling tile.

Materials for the study: The population for this study were discarded Polyethylene Terephthalate (PET) and High-Density Polyethylene (HDPE) plastics. These plastics include the common wastes found around in
Ogun State. Discarded PET and other types of plastics that include HDPE plastics products are in abundance as wastes along the streets, waterways and drains in Ogun State. There are waste plastics processing centres in Ogun State, where different types of waste plastics are crushed into chips in readiness for sale to recyclers. These waste plastics processing centres include that in Onihale, Ogun State, where different plastic wastes were found and crushed to chips. Among the plastic wastes found around in abundance is PET plastics used for making beverages plastic bottles like that of Fanta, coca-cola, pepsi-cola and table water of different kinds. HDPE is another common plastic wastes found in abundant next to PET which is used for cosmetic containers, milk jugs, automobile servicing oil and other containers.

Methods in use: The ceilings in use recently in Ogun State include the dry wall ceiling which is underside of the suspended floor slab. This is found in place where the building possesses upper floor (s) or constructed with concrete roof. Other common types of ceiling include suspended ceilings, where the arrangement of nogging members and ceiling boards are used to cover the upper surface of building rooms. Any of different types of ceiling tiles/boards is applicable in suspended types of ceiling. The common materials in use for suspended ceiling boards today include asbestos, Plaster of Paris (POP), woods and wood products and Polyvinyl Chloride (PVC). Most of these materials originated from Foreign countries and originally fashioned out to suit Foreign weather condition, at the same time very expensive. Since they are not locally fashioned out materials for the purpose of environmental condition of Ogun State, they are not the best option of ceiling tiles/boards materials for use in the state. Most of the industries that used these materials to produce ceiling tiles/boards recently in Ogun State are under the licence of the Foreign countries. Thus, ceiling tiles/boards used in Ogun State are Foreign goods. Hence the researcher chose to embark on this study, with the use of locally sourced materials for a ceiling tile.

Method used in the study: The method used to solve the existing problems associated with ceiling tiles/boards was the production of recycled HDPE and PET plastics ceiling tile. This was to adequately provide solution to the existing problems posed by the available ceiling tiles/boards in Ogun State.

Towards combating the problems associated with ceiling tiles/boards, the researcher made use of discarded PET plastics as main ingredient with HDPE as additive (reinforcement) to improve the quality of the recycled HDPE and PET plastics ceiling tile. The production process involved purchasing of crushed HDPE and PET plastics (chips), from a plastic waste processing centre. The uncrushed wastes of these plastics were also picked 
along the streets for the production of the ceiling tile. Picking of these plastics was very easy because of the plastic identification sign/code at the base of every recyclable plastic bottle/container. The PET is identified with number 1 when HDPE is number 2 as indicated in three chasing arrow sign at the bottom of the plastic products. Two sets of trial productions were carried out. The first set of trial production was in three phases and was meant to discover the exact quantity of materials needed for the production without wastage. The second trial productions were three samples of Recycled HDPE and PET ceiling tile, one was with pure PET plastic without reinforcement while the other two possessed ratio 1:9 and 1:4 of HDPE and PET plastics, respectively. However, the researcher wanted to discover the best mix proportions for the production of a ceiling tile, with good adhesive and flexural properties through the second set of trial production.

Production process: The production process includes activities that involved production materials composition, method of production, production equipment and sequence of production.

Production materials: Production materials for recycled High Density Polyethylene (HDPE) and Polyethylene Terephthalate (PET) ceiling tile include discarded PET plastics as major ingredient and HDPE plastic wastes as additive (reinforcement). Prior to the production towards discovering the adequate mixing proportion for the recycled HDPE and PET ceiling tile, there were initial trial productions, aimed at discovering the exact quantity of waste plastic chips, needed for the production for cost effectiveness and to avoid unnecessary excess of the production materials. These trial productions involved the use of trial measurements of $1.5,2$ and $3 \mathrm{~kg}$ for the productions before the use of $2.5 \mathrm{~kg}$ which was with negligible excess for the production size. Measurement in kilogram was adopted because of different sizes/weight of the discarded HDPE and PET plastic bottles/containers. The following trial productions were meant to determine the best mixing proportional ratio for the recycled HDPE and PET plastic ceiling tile.

Prototype A: This was composed of $100 \%$ of PET plastic wastes. In this, $2.5 \mathrm{~kg}$ of PET plastic waste chips was measured using $25 \mathrm{~kg}$ capacity camry scale.

Prototype B and C: Prototype B and C involved the use of $10 \%$ measure of HDPE plastic wastes chips $(0.25 \mathrm{~kg})$ along with $90 \%$ PET plastic waste chips $(2.25 \mathrm{~kg})$ in ratio $1: 9$. While prototype $\mathrm{C}$ was composed of $20 \%$ measure of HDPE plastic waste chips $(0.5 \mathrm{~kg})$ along with $80 \%$ of PET plastic waste chips $(2 \mathrm{~kg})$ in ratio 1:4. The reason was to enhance the adhesion and flexural property of the product through the two plastic waste materials.
Method of production: This involved the heating of the ingredients since this is the means of achieving melting state of thermoplastics plastic for easy moulding. The heating brought the plastic (s) wastes into almost liquid state that enabled the manipulations to achieve the desired production size and shape.

Production equipment: The production equipment used in this study includes gas stove for heating, a container in form of cooking pot to accommodate HDPE and PET plastic chips while heating. Other equipment include stirring stick for stirring the molten plastic and the mould with internal dimensions equal to the desired size of recycled HDPE and PET ceiling tile. These equipment items were made available for the production process in this study.

Sequence of production: The sequence of production followed the steps stated as follows:

- Arrangement of the production equipment in different suitable positions. These equipment were measuring scale, gas stove, heating container (pot), stirring stick and mould along with clothes which were soaked with cold water for cooling during curing

- Measurements of the ingredient(s) for the production

- Heating of the ingredient (s)

- Stirring of the molten plastics after removal from the heating stove. This enables the removal of bubbles that could cause air space in the ceiling tile product

- Pouring of the molten plastic into the mould placed on spread wet clothes

- Spreading of the molten plastic to occupy the entire inner space of the mould

- Covering of the molten plastic in mould with wet clothes for cooling during curing

- Removal of the product from the mould

- Examining the handling of the new product as a unit

- Necessary tests on the new ceiling tile product, to ascertain the quality

Identification of detail design: The detailed design of the recycled High Density Polyethylene (HDPE) and Polyethylene Terephthalate (PET) plastics ceiling tile production include the behaviour/workability of the materials and equipment to be used in the production of recycled HDPE and PET plastic ceiling tile.

Production materials: The main material considered in this study for the production of ceiling tile is Polyethylene Terephthalate (PET) plastic wastes. Another waste plastic considered as additive is High-Density Polyethylene (HDPE), the two types of plastics are thermoplastics. 
Richardson (2009) stated that thermoplastic plastics can be recycled by reheating to melt and remould to desired new shape and size.

PET plastic wastes: These were the most pronounced ingredient of the recycled High Density (HDPE) and Polyethylene Terephthalate (PET) ceiling tile of this study. The hygienic property of PET plastic makes it useful for packing food items, like beverages of different kinds (PI, 2016). Berins (1991) stated that, PET type of plastic has excellent heat resistance and easy to process. LeBlanc (2016) also stated that, PET plastic is widely used for recycling purposes. LeBlanc (2016) stated further that new produced polyethylene terephthalate is abbreviated to PET while recycled polyethylene terephthalate plastic is referred to as RPET.

HDPE plastic wastes: These are common among wastes plastics found around in Ogun State. High-Density Polyethylene (HDPE) is ranked number 2 in the ranking of recyclable plastics. Abdul (2016) stated that HDPE is a polyethylene thermoplastic made from petroleum. Thus, it belongs to the same family with PET and possesses softer nature relative to PET. Abdul (2016) stated further that, HDPE has density of greater or equal to $0.941 \mathrm{~g} \mathrm{~cm}^{-3}$, has a low degree of branching and thus possess stronger intermolecular forces and tensile strength. PI (2016) stated that HDPE represent the highest portion of the polyethylene applications, offers excellent impact resistance, light weight, low moisture absorption and possesses high tensile strength. HDPE is found widely used for different containers and toys among others. HDPE wastes are abundantly found on the streets and at plastic wastes processing centres in Ogun State. These attributes made the researcher to consider it as additive, in the production of a ceiling tile. The purpose of HDPE was to hold the molecules of the recycled HDPE and PET ceiling tile together and prevent cracking. There are two categories of plastics: Thermoplastic and thermosetting plastics; PET and HDPE belong to thermoplastic category. Richardson (2009) and Klein (2011) revealed that both categories of plastic are recyclable. While thermoplastic types can be reheated to molten state and remoulded, thermosetting can be ground to small particles and either bonded together with molten thermoplastic plastic or other binding agents. However, in this research study, there is intension to melt the discarded PET and HDPE plastics by heating and re-moulding to suitable shape and size required of recycled HDPE and PET ceiling tile.

Production equipment: Production equipment includes gas stove, heating container (pot), stirring stick and mould.
Heating equipment: This was gas cylinder filled with cooking gas that supplied heating flame through its overhead gas burner.

Mould: This is a separate unit that was made of sheet metal. It was fabricated with its internal dimensions equal to the desired size of the recycled HDPE and PET ceiling tile. It has a cover hinged to the mould and secured together when necessary with bolt and nut; that is, when not in use. The inside portion of the mould was worked to $460 \mathrm{~mm}^{2}$ with $12 \mathrm{~mm}$ depth.

Task involved: The task involved was the production of ceiling board with waste PET plastics as major ingredients and HDPE plastic wastes as additive (reinforcement). The production processes involved, two sets of trial productions. The first set involved four trial productions to determine the exact quantity of materials needed for the purpose of cost effectiveness. While the second set of trial productions involved three alternatives ("A", "B" and "C"), to determine the best mixing proportion for the recycled HDPE and PET ceiling tile.

Alternative "A" had PET plastics as the only ingredient which when heated to molten state was poured into the mould to assume the size and shape predetermined, through the mould. This process is similar to the casting method of producing mouldable plastics (Richardson, 2009). The process involved the application of heat to change plastic to molten state, before pouring into the mould to form the desired shape. Once the materials became cooled and hardened, the newly formed object was removed from the mould in readiness for the production of another batch.

Alternative "B" and " $\mathrm{C}$ " involved the addition of HDPE and PET plastic wastes in the production process. The process followed the same pattern as that of prototype " $\mathrm{A}$ ". This production was carried out in two batches; with materials composition of ratio 1:9 (10-90\%) and ratio 1:4 (20-80\%) of HDPE to PET plastic wastes in alternatives "B" and "C", respectively.

As soon as each alternative sample of recycled HDPE and PET plastic ceiling tile become set, it was removed from the mould for necessary tests. Tests were conducted to ascertain the efficiency of the new product comparatively, with the available ceiling tiles/boards in the market.

Description and development of the study: Ceiling tiles/boards are normally flat and square in shape while the size depends on the manufacturer of each product type. However, the size of the space to be sealed with ceiling tiles/boards mostly requires the sawing of some ceiling tiles/boards to fit the ceiling space. The sizes in use by CGC (2010) as recorded ranges from 
$300-600 \mathrm{~mm}^{2}$. The PVC ceiling tiles come in strip of $150 \mathrm{~mm}$ wide, POP ceiling depends on the size of the space to be sealed. Therefore, for the purpose of this study, a mould with internal size of $450 \mathrm{~mm}^{2}$ with $12 \mathrm{~mm}$ deep was provided for the recycled HDPE nd PET ceiling tile production. The production involved the use of pure PET plastic in prototype $A$ and mixing ratio of $1: 9$ and 1:4 of HDPE to PET plastic waste chips in prototype "B" and "C", respectively. The HDPE and PET ceiling tile was prescribed to be used and fixed in a similar way to other ceiling boards/tiles which are secured to the underneath of roof through nogging in a room. The nogging members for recycled HDPE and PET ceiling tiles are rebated in order to secure the board to the nogging and hold with narrow strips of wood to the nogging. There was hope that recycled HDPE and PET ceiling tile, would provide good outlook and quality suitable for use in construction of building.

Test techniques: The selected tests considered to be carried out on the recycled High Density Polyethylene (HDPE) and Polyethylene Terephthalate (PET) ceiling tile product include handling, water/moisture absorption, density, fire resistance, sound/acoustic effect, flexural and thermal insulation. However the researcher chose Metallurgical and Material Technology Laboratory, University of Lagos for tests of the recycled HDPE and PET ceiling tile. The choice of the laboratory was due to the availability of some of the material testing facilities/equipment. The tests were to ascertain the suitability of the recycled HDPE and PET ceiling tile, relative to the available ceiling tiles/boards for building construction purposes.

Water/moisture absorption test: This refers to the uptake of liquid into the fibre of a substance. It is necessary to conduct this test because of the danger involved in moisture absorption in building. Seeley (2010) stated that water absorbed in building can lead to deterioration, damage the finishing and adversely affect the health of the occupants. It is therefore necessary to consider moisture absorption of ceiling board, being the part that covers the room space above and can emit evaporated moisture into the room which in turn can affect the occupant's health.

The method of determining moisture absorbent rate adopted by Sanjeevamurthy and Srinivas (2012) was adapted in this research. This includes the measurement of dry Weight $\left(\mathrm{W}_{0}\right)$ before immersion into water and measurement of wet Weight $\left(\mathrm{W}_{1}\right)$ after the absorption of the water. Therefore, the absorption test activities included weighing each of the samples under testing in dry state to determine the Weight in grams $\left(\mathrm{W}_{0}\right)$. The next activity is the soaking of the specimen in water at room temperature for about 8,12 and $24 \mathrm{~h}$, each on different occasions this is in line with the varying timing used in Sanjeevamurthy and Srinivas (2012). The last stage is the wiping of the water away from the surface of the specimen, before weighing again to determine the Weight in grams $\left(\mathrm{W}_{1}\right)$ of the soaked specimens. The calculation formula to determine the percentage Moisture Content (MC) is as follows (Sanjeevamurthy and Srinivas, 2012):

$$
\mathrm{MC}(\%)=\frac{\mathrm{W}_{1}-\mathrm{W}_{0}}{1} \times 100
$$

This is to reveal the rate at which each material absorbs moisture. By standard if the absorbent value can be zero it is better, the more the absorption value reduces, the better the ceiling board. However, the standard used as reference point is $30 \%$ moisture content value. This is the stated standard percentage of moisture content value for construction materials in line with Fick's law (Health and Safety Executive, 2016).

Fire resistance test: The primary considerations in fire resistance construction are during designing and materials selection. Thus, materials used in construction of buildings determine the resistance against fire in a building. Milke et al. (2002) described the burning behaviour of materials as, once a material is ignited, fire spreads across the fuel object until it becomes fully involved. Thus, when fire emanates through any source close to ceiling tile; such ceiling tile needs to considerably resist the spread of fire for reasonable period of time. The equipment for testing fire resistance accurately is not available in the laboratories visited. However, partial fire resistance test was carried out using flame against the specimens to determine the ignition time, this proved considerable resistance to fire ignition. Since, this is not a standard method of testing fire resistance, it is not reliable.

Thermal insulation test: Laudis (2009) stated that thermal insulation materials are used to reduce the flow of heat between hot and cold regions. Therefore, it is necessary to consider thermal insulation properties of the ceiling tile, if the standard equipment for the test is available to ascertain the rate of the product's thermal resistance. The materials (High Density Polyethylene (HDPE) and Polyethylene Terephthalate (PET) plastics) used for the study possess considerable resistance to heat effects (PI, 2016). The formula for calculating thermal conductivity by Laudis (2009) is as stated as follows:

$$
\text { Thermal conductivity }=\frac{\text { Heat flow rate }}{\text { Area } \times \text { Temperature }}
$$


Acoustic test: Seeley (2010) stated that, when sound makes contact with a building surface such as a wall, floor or ceiling, part will be reflected back into the room, part will be absorbed by the materials of which the element is constructed. Therefore, acoustic test is considered necessary in this study, to ensure that the ceiling tile product controls any form of sound interference in the room where it will be used. This can only be done with standard testing equipment for acoustic control.

Decisions on the study tests: Based on the results of the comparative tests/assessment conducted in this study, the following decisions were taken: a sample of the ceiling tile with the lowest value of water absorption would be considered the best among other samples of the ceiling boards presented for water absorption test. A sample of the ceiling tile with the very good result in fire resistance test would be considered the best among other samples of the ceiling boards in fire resistance a sample of the ceiling tile, with very good result of assessment in thermal insulation test, would be considered the best, among other samples of the ceiling tiles/boards in thermal insulation a sample of the ceiling board with very good result of test in sound control would be considered the best, among other samples of the ceiling tiles/boards in sound control.

\section{RESULTS AND DISCUSSION}

Research question 1: What are the standard properties of a ceiling tile, in the High Density Polyethylene (HDPE) and Polyethylene Terephthalate (PET) plastics production materials for a ceiling tile?

Table 1 revealed the properties of the materials used for the production of recycled High-Density Polyethylene (HDPE) and Polyethylene Terephthalate (PET) ceiling tile. Item 1 shows that the two materials used are not good water absorbents. This indicates that their product would not harbor moisture and bacteria and as a result would not decay or rot. Item 2 revealed that HDPE and PET plastic materials have good mechanical strength property which implies that the product of these plastics would possess good strength. Item 3 revealed that HDPE is light weight which is a good quality of ceiling board that is not expected to impose much load on building structure, being non-structural component. Item 3 on this table also show that PET possesses good weather resistance. This would in turn make the recycled HDPE and PET ceiling tile product of these materials, resist weather conditions that may be harmful to human being. Item 4, Table 1 show that HDPE plastic is nontoxic while PET plastic has good resistance to high energy radiation. These properties indicate that, the two materials would contribute to the health friendly quality expected of recycled HDPE and PET plastic ceiling tile. Item 5 of the table also revealed that HDPE and PET are not dangerous, when in contact with food which meant that touching recycled HDPE and PET ceiling tile while eating would not cause health danger, through food with the use of the two plastics. Item 6 in Table 1 revealed that HDPE is non-staining while PET has very good chemical resistance. These properties of HDPE and PET plastics show that the recycled HDPE and PET ceiling tile would be easy to clean and without accommodating stain. Item 7 revealed that HDPE is thermoforming while PET is a good electrical insulator. However, the two materials possess thermoform quality and are good electrical insulator; as a result, a product through HDPE and PET would not pose any danger through any form of contact with electricity.

Research question 2: What exact quantity of High Density Polyethylene (HDPE) and Polyethylene Terephthalate (PET) plastic production materials is adequate for the production of ceiling tile, for the purpose of cost effectiveness?

Table 2 show the trial productions of recycled HDPE and PET ceiling tile, towards detecting the adequate quantities of material for the production, to avoid unnecessary wastage. In the first and second trial production, 1.5 and $2.0 \mathrm{~kg}$ of HDPE/PET plastic wastes were used, respectively, these quantities were found inadequate for the size of the expected recycled HDPE and PET ceiling tile. Trial production on item 3, Table 2 shows that $3.0 \mathrm{~kg}$ of HDPE/PET waste plastics was used in the third production, this was found excessive for the production. Table 2, item 4 equally reflected the use of $2.5 \mathrm{~kg}$ of PET plastic waste in the fourth attempt which was found adequate with negligible excess. The outcome of these trial productions, therefore shows that $2.5 \mathrm{~kg}$ of plastic waste materials is adequate for the production of recycled HDPE and PET plastic ceiling tile of $450 \mathrm{~mm}^{2}$ with $12 \mathrm{~mm}$ thickness.

Table 1: Properties of a ceiling tile, in High Density Polyethylene (HDPE) and Polyethylene Terephthalate (PET) plastics used for a ceiling tile

\begin{tabular}{lll}
\hline Items & High-Density Polyethylene HDPE) & Polyethylene Terephthalate (PET) \\
\hline 1 & Low moisture absorption & Low water absorption \\
2 & High tensile strength & High mechanical strength \\
3 & Light weight & Good weather resistance \\
4 & Non-toxic & Good resistance to high energy radiation \\
5 & Meets FDA/USDA food guidelines & In compliance with FDA and CFR177.1630 for use in contact with food \\
6 & Non-staining & Very good chemical resistance \\
7 & Thermoforming performance & Good electrical insulator \\
8 & - & Excellent wear resistance \\
\hline
\end{tabular}


Research question 3: What mix ratio of High Density Polyethylene (HDPE) and Polyethylene Terephthalate (PET) plastics production materials, would meet the adhesive and flexural property of a ceiling tile? To answer research question 3 , the report of the production processes shown in table 3 and the flexural test result in Table 4 were used. The productions with different mix ratios were in three phases: A, B and C. Table 3 shows three mix ratios of materials for the production of recycled HDPE and PET ceiling tile. As revealed in Table 3, phase A where pure PET plastic waste was used yielded a product with unstable adhesion. It could not be carried as unit showing that reinforcement is required with the PET plastic wastes. Phase B on table 3 revealed that the production with mix ratio 1:9 of HDPE and PET plastic wastes was stable. This yielded a product with partial adhesion, showing that addition of HDPE plastic wastes could improve the adhesion of the ceiling tile of the study.

Table 2: Data of the HDPE and PET plastic production materials quantity used in the trial productions of recycled HDPE and PET ceiling tile, for the purpose of cost effectiveness

\begin{tabular}{lcl}
\hline Production & HDPE/PET plastic wastes quantity $(\mathrm{kg})$ & Remark \\
\hline 1 & 1.5 & Inadequate \\
2 & 2.0 & Inadequate \\
3 & 3.0 & Excessive \\
4 & 2.5 & Adequate \\
\hline
\end{tabular}

Table 3: Result of mix ratio of HDPE and PET production material(s) used in three phases of production of recycled HDPE and PET ceiling tile, on adhesive and flexural properties

\begin{tabular}{llcl}
\hline Phase & Material & Ratio & Outcome \\
\hline A & Pure PET & NIL & Broken \\
B & HDPE+PET & $1: 9$ & Partial adhesion \\
C & HDPE+PET & $1: 4$ & Stable adhesion \\
\hline
\end{tabular}

Table 4: Result of the flexural test, carried out on the prototype C, for the recycled HDPE and PET ceiling tile

\begin{tabular}{lc}
\hline Item & Maximum flexural test (MPa) \\
\hline 1 & 1.023 \\
2 & 1.570 \\
Mean standard & 1.297 \\
minimum value & 0.080 \\
\hline
\end{tabular}

Table 3 also revealed that in phase $\mathrm{C}$, mix ratio 1:4 of HDPE and PET plastic wastes was used in the production of the ceiling tile. This yielded a stableadhered recycled HDPE and PET ceiling tile of the study. As a result, the use of HDPE plastic waste was found useful to improve the adhesive property of recycled HDPE and PET ceiling tile.

Table 4 shows the result of flexural test carried out on product "C" with the use of 3-point flexural testing equipment. The test procedure sheet and graph were shown in Fig. 1.

Table 4 shows that the test was carried out 2 times. The first test revealed $1.023 \mathrm{MPa}$ flexural property value of recycled HDPE and PET ceiling tile. This indicated that the product was slightly flexible at the point of the first test and more rigid. The second test revealed $1.570 \mathrm{MPa}$ which was improvement over the first test. The implication is that, there was concentration of reinforcement on the second specimen used for the test. The mean result of the two flexural tests revealed in Table 4 was $1.297 \mathrm{MPa}$. This value is above the stated flexural minimum value expected of ceiling tile. The implication is that the recycled plastic ceiling tile is rigid with moderate flexibility that prevents damage of the product during storage, transportation and usage.

Research question 4: What production method is most appropriate for the production of recycled HDPE and PET plastic ceiling tile?

Table 5 revealed different methods of producing different plastic products. Products in items 1-7 do not depict the shape and outlook of ceiling board. Item 8 on the table reveals that casting method could be manipulated to give desired shapes. Therefore, the principle involved in casting method of plastic production (Richardson, 2009), was adaptable for the production of recycled HDPE and PET plastic ceiling tile.

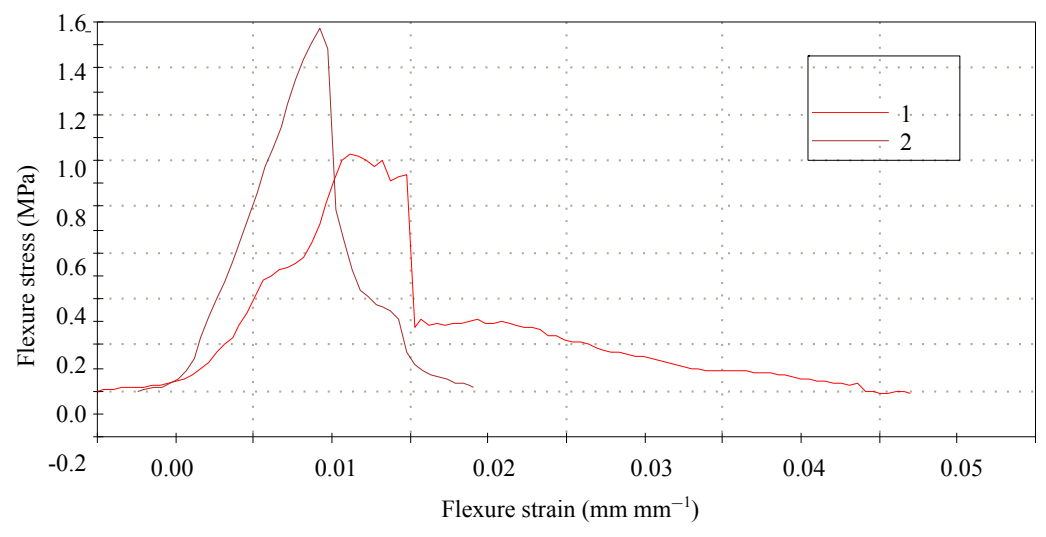

Fig. 1: Flexural test on recycled HDPE and PET ceiling tile specimens 
Table 5: Production methods of thermoplastic plastics

\begin{tabular}{lll}
\hline Items & Thermoplastic plastics production method & Products \\
\hline 1 & Injection moulding & Toys, combs, car grills and containers \\
2 & Extrusion method & Fabrics for clothes, curtains and carpets. \\
3 & Blow moulding & Bottles, hollow thermoplastic tubes and other containers \\
4 & Blow film extrusion & Plastic garbage bags and continuous sheets. \\
5 & Calendaring & Plastic sheets for flooring and wall siding tape \\
7 & Compression moulding & Dinner-ware, telephones, television set frames and electrical parts \\
8 & Casting & Mouldable products \\
\hline
\end{tabular}

Table 6: Results of the physical/mechanical tests carried out on the recycled HDPE and PET Plastic ceiling tile

\begin{tabular}{|c|c|c|c|c|c|c|}
\hline Items & Tests & $1 \mathrm{st}$ & 2nd & $3 \mathrm{rd}$ & Mean & Standard \\
\hline 1 & Water absorption $(\%)$ & 0.70 & 0.73 & 0.71 & 0.713 & Maximum of $30 \%$ \\
\hline 2 & Water Permeability & Nil & Nil & Nil & Nil & Impervious \\
\hline 3 & Flexural (MPa) & 1.02 & 1.6 & - & 1.31 & Minimum of 0.08 \\
\hline 4 & Texture & Slightly smooth & Slightly smooth & Slightly smooth & Slightly smooth & Smooth \\
\hline 5 & Workability & $\begin{array}{l}\text { Can be sawn and } \\
\text { sandpapered }\end{array}$ & $\begin{array}{l}\text { Can be sawn and } \\
\text { sandpapered }\end{array}$ & $\begin{array}{l}\text { Can be sawn and } \\
\text { sandpapered }\end{array}$ & $\begin{array}{l}\text { Can be sawn and } \\
\text { sandpapered }\end{array}$ & Workable \\
\hline 6 & Surface treatment & Can be painted & Can be painted & Can be painted & Can be painted & Optional \\
\hline 7 & Fire resistance & - & - & - & - & - \\
\hline 8 & Thermal insulation & - & - & - & - & - \\
\hline 9 & Acoustical value & - & - & - & - & - \\
\hline
\end{tabular}

Source: Metallurgical/material technology laboratory, University of Lagos

Every method involved the melting of the plastic materials in the process. Casting methods of producing plastics include the use of mould inside which the molten plastic is poured to form the desired shape and size of the product.

Research question 5: What are the properties of the produced recycled HDPE and PET plastics ceiling tile?

Item 1 in Table 6 revealed the mean of water absorption test as $0.71 \%$ while item 2 shows the result of inability of water to penetrate through the recycled HDPE and PET ceiling tile samples. These show that recycled HDPE and PET ceiling tile does not allow the retention of water in its internal texture; as a result has no tendency of retaining bacteria through humid radiation. The tendency of fungi growth and decay is very low as the ceiling board would not retain moisture. More importantly, the mean of moisture absorption value of 0.713 revealed in item 1 is far below the standard maximum value expected of ceiling tiles. Items 3 Table 6 revealed the mean result of flexural tests on recycled HDPE and PET ceiling tile as $1.31 \mathrm{MPa}$. This value is conveniently above the minimum stated standard value of $0.08 \mathrm{MPa}$ flexural strength expected of a ceiling tile. The flexural test result depicts that recycled HDPE and PET ceiling tile product is rigid and would provide enough flexibility that enables safe handling of the product, without damages during storage, transportation and construction.

Table 6 also revealed the outcome of the assessments on the texture, work ability and surface treatment in items 4,5 and 6 , respectively. These show that the recycled HDPE and PET ceiling tile has slightly smooth texture which means that the surface texture can be manipulated to receive surface treatment to enhance the aesthetic of the product. The results on work ability and surface treatment also revealed that the product could be sawn and sand-papered while the surface can be treated with paints. This reveals that, the recycled HDPE and PET ceiling tile could be manipulated to suit any desired result during construction.

Item 7, 8 and 9 in Table 6 reveal the inability to assess the product for fire resistance, thermal insulation and acoustics. This is due to none availability of testing equipment on these properties. As a result, the researcher cannot determine the fire resistance, thermal insulation and acoustic properties of recycled HDPE and PET ceiling tile. However, the properties tested, could make the product useful where those properties are more essential.

Research question 6: What are the differences in the qualities of recycled High Density Polyethylene (HDPE) and Polyethylene Terephthalate (PET) plastic ceiling tile and the common available ceiling tiles which are asbestos, Plaster of Paris (POP) and Polyvinyl Chloride (PVC)?

Table 7 revealed eight items of comparison test results of recycled HDPE and PET ceiling tile and the common available ceiling tiles/boards that include: asbestos, Plaster of Paris (POP) and Polyvinyl Chloride (PVC). Item 1 reveals that recycled HDPE and PET and PVC ceiling tiles have water absorption value of $0.7 \%$ and $0.5 \%$, respectively. These show that, the two ceiling boards are not water absorbent materials and there is no tendency of their harbouring bacteria or fungi that may endanger building users' health or cause the ceiling board to decay and collapse. Item 1 Table 7 also reveals that, asbestos and POP is water absorbent materials, meaning that they could harbour bacteria, grow fungi and could decay as well dangerous to human health. Item 2 Table 7 
Table 7: Comparison of recycled HDPE and PET ceiling tile and the common available ceiling boards (asbestos, plaster of paris and Polyvinyl Chloride)

\begin{tabular}{|c|c|c|c|c|c|}
\hline Items & Property & HDPE/PET & Asbestos & POP & $\mathrm{PVC}$ \\
\hline 1 & Water absorption (\%) & 0.7 & 22 & 26 & 0.5 \\
\hline 2 & Water permeability & Very impervious & Impervious & Impervious & Very impervious \\
\hline 3 & Texture & Slightly smooth & Slightly smooth & Smooth & Very smooth \\
\hline 4 & Workability & Can be sawn and sandpapered & Can be sawn & Can be sawn & Can be sawn \\
\hline 5 & Surface treatment & Can be painted & Can be painted & Can be painted & Cannot receive paint \\
\hline 6 & Fire resistance & - & - & - & - \\
\hline 7 & Thermal insulation & - & - & - & - \\
\hline 8 & Acoustical value & - & - & - & - \\
\hline
\end{tabular}

shows that all the ceiling tiles/boards are impervious but recycled HDPE and PET and PVC ceiling tiles are very impervious. This is because the materials used for recycled HDPE and PET and PVC ceiling tiles are plastic based as a result do not permit the penetration of water that may damage the ceiling board or cause collapse of the ceiling.

Item 3 Table 7 shows that texture of recycled HDPE and PET ceiling tile is slightly smooth along with that of asbestos and POP ceiling boards. This implies that, the outlook of recycled HDPE and PET ceiling tile could receive and retain surface treatment as in the case of asbestos and POP ceiling tiles. However, PVC ceiling board with very smooth texture cannot retain surface treatment if required. Items 4 and 5 Table 7 revealed that recycled HDPE and PET ceiling tile could be sawn and sandpapered during construction while its surface can be treated with paint of any desired type and colour. Item 4 Table 7 revealed that asbestos and POP ceiling boards equally possess the same work ability and surface treatment characteristics with recycled HDPE and PET ceiling tile. This item shows that PVC ceiling board can only be sawn to size but cannot receive paint. Items 6,7 and 8 Table 7 revealed no result for the fire resistance, thermal insulation and acoustic value comparisons of recycled HDPE and PET ceiling tile and the available ceiling tiles/boards. This is due to none availability of testing equipment to test the properties of fire resistance, thermal insulation and acoustic value of the samples provided. As a result, recycled HDPE and PET ceiling tile may not be recommended where the properties of fire resistance, thermal insulation and acoustic performance are essential.

Generally, in the comparison of recycled HDPE and PET plastic ceiling tile with other ceiling tiles/boards, it compete favourably in all the possible comparison tests carried out. The table revealed that, recycled HDPE and PET ceiling tile, outweighed PVC in the properties of work ability and surface treatment. On the other hand, it outweighed asbestos and POP in water absorption and water permeability which are very critical properties expected of a good ceiling tile/board. Meanwhile, recycled HDPE and PET ceiling tile can be sawn like asbestos and POP ceiling boards. Thus, recycled HDPE and PET ceiling tile would be useful, where those properties that could not be tested, are not essential. However, other available ceiling tiles could not be tested as well, where the testing equipment was not available. It is therefore, difficult to judge the rank of recycled HDPE and PET ceiling tile, in the properties of fire resistance, thermal insulation and acoustic value.

Findings of this study revealed that, the properties of materials for the production of recycled High Density Polyethylene (HDPE) and Polyethylene Terephthalate (PET) ceiling tile determine its output characteristics. The two materials chosen for the production of recycled HDPE and PET ceiling tile, are not water absorbents. This indicated that the product would not allow penetration of moisture as a result, would not harbour humid moisture that could accommodate bacteria. At the same time, the product would not decay or rot. Occupational Safety and Health Administration OSHA (2002) and Marquis (2009) stated that absorbed moisture in a material can harbour bacteria and release them to the environment through evaporation. Washington State Department of Health WSDH (2011) does not support the use of absorbent material for building construction. The materials chosen for production of recycled HDPE and PET ceiling board have good mechanical strength, light in weight and also possess good weather resistance characteristics. Other characteristics of High Density Polyethylene (HDPE) and Polyethylene Terephthalate (PET) plastics are good resistance to heat and high energy radiation. Above all, HDPE and PET plastics are not dangerous when in contact with food. PI (2016) stated that PET plastic is in compliance with United States Food and Drugs Administration (FDA) regulation CFR 177.1630 for use in contact with food while HDPE meets Food and Drugs Administration/United States Department of Agriculture (FDA/USDA) food handling guidelines. The findings show that the choice of HDPE and PET plastic wastes as materials would contribute a great deal in achieving a type of ceiling board with very good qualities expected of it.

It was found that four different quantities of materials were used in the trial productions of the HDPE and PET ceiling tile. The quantities of materials used include $1.5,2.0,3.0$ and $2.5 \mathrm{~kg}$. Out of these materials quantities used in trial production, $2.5 \mathrm{~kg}$ of the materials was 
found adequate for the production of recycled HDPE and PET plastic ceiling tile, with negligible left over. Determination of the exact material input needed in the production is necessary, to avoid wastage of materials and for cost effectiveness of the output. Velasco (2011) also stated that the total cost of input is equal to the output cost. Thus, it is necessary to determine the quantity of material (s) used in a production of recycled HDPE and PET ceiling tile, to ascertain the cost.

Findings of this study also reveal different proportions of materials used in the production of recycled HDPE and PET ceiling tile. The ratios used include full measure $(2.5 \mathrm{~kg})$ of pure PET plastic waste chips, ratios 1:9 and 1:4 of HDPE to PET plastic waste chips. Measurement of this nature is necessary in order to ensure maximum use of Polyethylene Terephthalate (PET) plastic. This is because PET has been identified to be the most advantageous material for the production of recycled HDPE and PET ceiling tile. MatWeb (2016) gave the melting point of PET plastic as $250^{\circ} \mathrm{C}$ while that of $\mathrm{HDPE}$ is $135^{\circ} \mathrm{C}$. Since the high melting point determines high heat resistance, it is necessary to determine smaller quantity of the additive and the bigger quantity of the main material. This is to ensure the high performance of the product. The mix ratio of 1:4 of HDPE to PET mixture of the materials was found to give the best product of the recycled HDPE and PET ceiling tile with good properties. Thus, four portions of PET plastic as against one portion of HDPE plastic ratio of materials were mixed together to improve the adhesive and flexural properties of recycled HDPE and PET plastic ceiling tile. The result of flexural test carried out on the product with ratio 1:4 proportion of materials was $1.3 \mathrm{MPa}$, this was adequate enough to enable handling of the recycled HDPE and PET ceiling tile.

The findings of this study revealed that the type of material used for ceiling tile production determines the production method. That is, the production method of converting plastic to product would be applicable in the production of recycled HDPE and PET ceiling tile. The findings reveal list of different methods of producing plastic which include: injection moulding, blow moulding, extrusion method, blow film extrusion, cast moulding, calendaring and compression moulding (Richardson, 2009). The findings also revealed that each method of plastic production is for different plastic product. Among these methods, casting method was found most adaptable for the production of recycled HDPE and PET ceiling tile. The findings show that casting method of producing plastics can be used to produce plastic-base product to desire shape and size. Casting method of producing plastics includes the use of mould which can be fabricated to assume the shape and size of a desire product, inside which the molten plastic is poured to form desired shape and size of plastic product. The findings of this study revealed that recycled HDPE and PET plastic ceiling tile, possesses the properties of none absorbent and impervious to penetration of liquid. These properties imply that recycled HDPE and PET ceiling tile cannot retain bacteria that dwell in moisture. These properties make recycled HDPE and PET ceiling tile, a good ceiling tile. Marquis (2009) stated that bacteria normally dwell in moist place and causes diseases when they migrate out of the moist place into the environment through evaporation.

The findings also revealed the value of recycled HDPE and PET ceiling tile flexural property test result; this depicts that, the recycled HDPE and PET ceiling tile is rigid and possesses reasonable flexibility that enables safe handling of the product without damage during storage, transportation and construction. Other properties of recycled HDPE and PET ceiling tile revealed through the findings are: good surface texture, workable and treatable surface. These attributes show that recycled HDPE and PET ceiling tile, can be manipulated to receive surface treatment like painting, to enhance the aesthetic of the product. There were no facilities to carry out test on fire resistance, thermal insulation and acoustic control. However, the findings reveal that recycled HDPE and PET ceiling tile can be used in construction of building, where the need for fire resistance, thermal insulation and acoustic control is not essential.

The findings of this study revealed the differences in the qualities of the produced recycled HDPE and PET plastic ceiling tile and the available ceiling tiles/boards. The common available ceiling tiles/boards used in comparison tests are asbestos, POP and PVC ceiling tiles/board (Table 7). The comparison of recycled HDPE and PET ceiling tile with the available ceiling tiles/boards is necessary because it is a new product. Nworgu (2006) stated that production through research and development involved trial-testing in the field to ensure the effectiveness of the product. Research and development is also said to be means of producing new improved products (Levy, 2002). This shows the importance of carrying out a comparison tests on a new product with the available ones as a means to determine the effectiveness and improvement found in the new product, against the available ones. The result of comparison test is shown in Table 7.

The findings showed that recycled HDPE and PET ceiling tile and PVC ceiling boards are not water absorbent materials and there is no tendency of their harbouring bacteria or fungi that may endanger building users' health or cause the ceiling board to decay and collapse. The asbestos and POP are revealed to be water absorbent materials, meaning that they could harbour bacteria. Asbestos and POP ceiling boards were found 
impervious, when cycled HDPE and PET and PVC ceiling tiles, were more impervious. The textures of recycled HDPE and PET ceiling tile and asbestos ceiling boards were found slightly smooth while that of POP is smooth and PVC possesses very smooth surface texture. Recycled HDPE and PET ceiling tile could receive and retain surface treatment like painting, likewise that of asbestos and POP ceiling boards. The PVC ceiling board with very smooth texture cannot retain surface treatment if required. The findings also revealed that recycled HDPE and PET ceiling tile, could be sawn and sandpapered during construction. The surface of recycled HDPE and PET ceiling tile could be treated with paint of any desired type and color. The asbestos and POP ceiling boards equally possessed the same workability and surface treatment characteristics with recycled HDPE and PET ceiling tile. The findings revealed that PVC ceiling tile can only be sawn to size but cannot receive paint. However, the testing equipment for fire resistance, thermal insulation and acoustic control were not available at the material technology laboratories visited. Generally, the findings revealed that, the recycled HDPE and PET ceiling tile can be used in construction of building, where those properties that could not be tested are not essential.

Implications of the study: The recycled High-Density Polyethylene (HDPE) and Polyethylene Terephthalate (PET) ceiling tile production is useful for Ogun State Ministry of Education as one of the courses of study in her vocational training centres. It would go a long way in preparing youths for gainful employment. There would be more choices of course for individuals to embark upon in the training centres. The production of recycled HDPE and PET ceiling tile can be embarked upon in institution of learning that runs vocational and technical education as a means of internal generation of revenue. The production of recycled HDPE and PET ceiling tile, within the institution's environment would also serve as vocational skill acquisition means for any student that may like to acquire skills in the production of recycled HDPE and PET ceiling tile. The recycled HDPE and PET ceiling tile is a potential product for exhibition during any academic program that includes exhibition.

Since, there are waste plastics processing centres in Ogun State, it is an opportunity for the state Ministry of Education to draw a program of study on recycling of plastics that would include production of recycled HDPE and PET ceiling tile as means of practical training in secondary and technical colleges. This would serve as an opportunity for any student that passed through such schools, to have vocational skill for self-employment. The curriculum planners would have access to what the production of recycled HDPE and PET ceiling tile entails and work towards integrating its practical training in relevant courses of study.

\section{CONCLUSION}

Most of the available ceiling tiles/boards for construction recently in Ogun State, do not possess reasonable number of properties expected of a good ceiling tile/board. Polyvinyl Chloride (PVC) possesses very low heat resistance when compared with Polyethylene Terephthalate (PET) plastic counterpart. Ogun State which experiences periodic hot weather condition (dry season), requires the use of materials with reasonable heat and fire resistance. The available ceiling tiles/boards are expensive because they are of Foreign origin. Shortcomings of the available ceiling tiles/boards and the discovered advantages of PET plastic made the researcher to carry out this study. The study had therefore made the following contributions to knowledge and improvement in construction industry of Ogun State: Provided a new improved ceiling board for construction industry in Ogun State, created the opportunity for the industrial technical education curriculum planners to draw curriculum on the production principles of recycled HDPE and PET ceiling tile, provided additional material for architect to recommend for building construction, provided a new easy to use ceiling board with less risk of damages and danger to health for the builders and Made additional means of managing wastes for the waste managers in Ogun State.

\section{RECOMMENDATIONS}

Based on the findings of the study, the following recommendations were made. Ogun State Ministry of Education to integrate the production of recycled HighDensity Polyethylene (HDPE) and Polyethylene Terephthalate (PET) plastic ceiling tile, in vocational training centres of the state. This would go a long way in preparing youths for gainful employment. Vocational and technical institutions should embark on production of recycled HDPE and PET ceiling tile by using the findings of this study. Ogun State Ministry of Education should draw a program of study on recycling of plastics to include production of recycled HDPE and PET ceiling tile as practical training in secondary and technical colleges the curriculum planners should access what the production of recycled HDPE and PET ceiling tile entails and work towards integrating its practical training in relevant courses of study in schools and colleges

\section{REFERENCES}

Abdul, A., 2016. Polyethylene: Manufacturing and its properties. Academia, San Francisco, California, USA. https://www.academia.edu/3052708/ Polyethylene_Maufacturing_and_its_Properties

Aderogba, K.A., 2014. Polymer wastes and management in cities and towns of Nigeria and sustainable environment. Peak J. Phys. Environ. Sci. Res., 2: 1-12. 
Afuwape, M.A., 2013. Development of a model of water evacuator for property protection against flooding in built-up catchment. Ph.D Thesis, Department of Vocational Teacher Education, University of Nigeria, Nsukka, Nigeria.

Asante-Kyei, K., 2012. Manufacturing of local plaster of Paris (P.O.P.) from salt residue mined in Sege in the Dangme East District of the Greater Accra Region of Ghana. Res. J. Environ. Earth Sci., 4: 953-958.

Bachman, R. and S. Dowty, 2008. Non-structural components and nonbuilding structures. Build. Saf. J., 1: 1-4.

Bart, J.C.J., 2005. Additives in Polymers: Industrial Analysis and Applications. 1st Edn., John Wiley and Sons Ltd., The Netherlands, ISBN: 9780470850626.

Berins, M.L., 1991. Plastic Materials/Properties and Applications. In: SPI plastics Engineering Handbook of the Society of the Plastics Industry, Berins, M.L., (Ed.). Springer, Boston, Massachusetts, USA., ISBN:978-1-4615-7606-8, pp: 47-78.

CGC., 2010. Acoustical design and applications. Canadian Gypsum Company (CGC), Canada, North America.

Chuldley, R. and R. Greeno, 2014. Building Construction Handbook. Routledge, New York, USA., ISBN:9780415836388, Pages: 978.

Fox, J., 2008. Analysis of polymer additives in the packaging industry. University of Florida, Gainesville, Florida, USA. https://www.iopp.org/ files/public/FoxFloridaAdditives.pdf

GS., 2011. About us (PVC ceiling board manufacturing company). Golden Silk Industries (Nig) Ltd., Lagos, Nigeria.

Klein, R.H., 2011. Material Properties of Plastics. Wiley-VCH, Weinheim, Germany, Pages: 68.

Laudis, F., 2009. Installation: Microsoft encarta $\left({ }^{\circledR}\right.$ [DVD]. Microsoft Corporation, Redmond, Washington, USA.

LeBlanc, R., 2016. Recycling Polyethylene Terephthalate (PET). Lifewire, USA. https://www.thebalancesmb. com/recycling-polyethylene-terephthalate-pet2877869

Levy, D.M., 2002. Research and Development. 1st Edn., Liberty Fund Nonprofit, Indianapolis, Indiana, USA.,.
Marquis, R.E., 2009. Bacteria: Microsoft encarta ${ }^{\circledR}$ [DVD]. Microsoft Corporation Technology Company, Redmond, Washington, USA.

Milke, J., V. Kodur and C. Marrion, 2002. A Overview of Fire Protection in Buildings. Federal Emergency Management Agency (FEMA), Washington, D.C., USA.

Newman, J.L., A. Mehretu, K. Shillington and R. Stock, 2009. Africa: Climate: Microsoft Encarta ${ }^{\circledR}[D V D]$. Microsoft Corporation. Redmond, Washington, USA.

Nworgu, B.G., 2006. Educational Research: Basic Issues and Methodology. 2nd Edn., University of Nigeria, Nsukka, Nigeria,.

OSHA., 2002. Asbestos standard for the construction industry-occupational. Occupational Safety and Health Administration (OSHA), Washington, D.C., USA. https://www.osha.gov/Publications/ OSHA3096/3096.html

PI., 2016. Plastic data sheets. Plastic International, Eden Prairie, Minnesota, USA.

Richardson, T.L., 2009. Plastics. Microsoft Encarta ${ }^{\circledR}$ [DVD], Microsoft Corporation, Redmond, Washington, USA.

SABISA., 2013. General specification for suspended ceiling. South African Building Interior System Association (SABISA), Midrand, South Africa.

Sanjeevamurthy, G.C. and G.R. Srinivas, 2012. Sisal/coconut coir natural fibers-epoxy composites: Water absorption and mechanical properties. Intl. J. Eng. Innov. Technol., 2: 166-170.

Seeley, I.H., 2010. Building Technology. 5th Edn., Palgrave Macmillan, London, England, UK.

Velasco, M.S., 2011. Production theory. Linked In Corporation Company, Sunnyvale, California, USA. https://www.slideshare.net/salasvelasco/microecon omics-production-theory

WSDH., 2011. Acoustical ceiling materials: Guideline for Healthcare facilities. Washington State Department of Health (WSDH), Tumwater, Washington, USA. https://www.doh.wa.gov/Portals/1/Documents/230 0/505-079Appceilingtiles.pdfp 